\title{
Utilização de Técnicas Participativas no Processo Ensino-Aprendizagem sobre o Tema da Judicialização da Saúde: Relato de Experiência
}

\author{
Anna Maria Meyer Maciel Rodríguez, Tereza Cristina Scatena Villa, Silvana Martins Mishima \\ Escola de Enfermagem de Ribeirão Preto da Universidade de São Paulo
}

*Autores para correspondência: nimeyer5@hotmail.com; tite@eerp.usp.br; smishima@eerp.usp.br

\begin{abstract}
RESUMO
Trata-se de relato de experiência acerca do uso de ferramentas facilitadoras no processo ensino-aprendizagem junto a alunos de graduação em Enfermagem no contexto da disciplina Organização e Gestão em Saúde e Enfermagem na Atenção Básica, com vistas a auxiliá-los na compreensão e na reflexão quanto ao processo de judicialização da saúde. A disciplina é ministrada no sétimo período do curso de graduação em uma instituição pública de ensino universitário do interior paulista. Anteriormente à aula, os alunos receberam um artigo e uma reportagem atuais sobre o tema para leitura prévia. No dia da aula, utilizando a técnica brainstorming, as facilitadoras da discussão perguntaram aos alunos o que entendiam sobre o tema, anotando as respostas no quadro sem julgamentos. Em seguida, foi aplicada uma dinâmica de grupo, confeccionada de modo lúdico, visando a trazer o cenário internacional sobre o nascimento e a evolução dos direitos, o direito à saúde e a judicialização no Brasil. Então, expuseram-se dados sobre a situação da judicialização da saúde em um município paulista, e os alunos foram provocados à reflexão utilizando um dilema ético-moral indiretamente relacionado ao tema da aula. Eles se mostraram surpresos, receptivos e participativos com as técnicas usadas, cuja articulação os aproximou da realidade do município, proporcionou um resgate de vivências pessoais e instigou a reflexão sobre diversas e complexas questões relacionadas às necessidades individuais e coletivas e ao papel social do enfermeiro no processo de judicialização da saúde.
\end{abstract}

Palavras-Chave: Aprendizagem; Ensino; Educação Superior; Metodologias Ativas; Judicialização da Saúde.

\begin{abstract}
It is a related experience about the use of facilitating tools in the teaching-learning process, with nursing undergraduate students in the context of the discipline of Organization and Management in Health and Nursing in Primary Care, with a view to assisting them in the understanding and reflection of the process of health judicialization. The course is taught in the seventh period of the undergraduate course at a public institution of higher education in the interior of São Paulo. Previous to the class, the students received the current article and report on the subject for previous reading. On the day of the class, using the brainstorming technique, the facilitators of the discussion asked the students what they understood about the subject, noting the answers in the table without judgments. Then, a group dynamic was applied, made in a playful way, aiming to bring the international scenario on birth and the evolution of rights, the right to health and judicialization in Brazil. Afterwards, data on the situation of health judicialization in a municipality in São Paulo were presented and the students, were provoked to reflect using an ethical-moral dilemma indirectly related to the theme of the class. The students were surprised, receptive and participative with the techniques used, of which its articulation brought them closer to the reality of the municipality, provided a rescue of personal experiences and instigated reflection on diverse and complex issues related to individual and collective needs and the social role of the nurse in the process of health judicialization.
\end{abstract}

Keywords: Learning; Teaching; Higher Education; Active Methodologies; Health's Judicialization.

\section{Introdução}

A judicialização da saúde, tema que tem ganhado destaque no campo da saúde, aflora da premissa constitucional de que a "saúde é direito de todos e dever do Estado" (BRASIL, 2014, p. 133), que traduz a preocupação com os direitos e garantias fundamentais a todos os cidadãos e se coloca como elemento presente na implementação 
mais contemporânea das políticas públicas de saúde no Brasil. A discussão dessa temática junto aos cursos da área da saúde tem se feito presente em disciplinas voltadas às políticas de saúde, organização e gestão de serviços e sistemas de saúde.

A temática, por sua importância na formação de profissionais dessa área, traz o desafio de ser tratada, no âmbito do processo ensino-aprendizagem, de modo instigante e que produza significados junto aos alunos que terão em sua vida profissional dilemas voltados à questão do direito à saúde.

$\mathrm{O}$ uso de técnicas participativas em sala de aula, tais como brainstorming ou tempestade cerebral, dinâmicas de grupo e debate com a sala toda, tem se mostrado um facilitador do processo ensino-aprendizagem, quebrando a perspectiva bancária e possibilitando o processo reflexivo dos estudantes. Assim, essas estratégias educativas vêm sendo utilizadas para estimular a participação dos alunos com a possibilidade de deixar sua passividade de lado ao construírem o conhecimento de maneira ativa e coletiva (MASETTO, 2015). Adicionalmente, podem despertar e exercitar nos alunos diversas operações de pensamento, dentre elas: a experimentação e a reflexão, na medida em que resgatam sua vivência pessoal e conectam o saber com o fazer apropriando-se do conteúdo didático (ANASTASIOU \& ALVES, 2005).

O docente pode, em sua prática pedagógica, além de aplicar metodologias ativas de ensino como opções didáticas, estabelecer relações entre o conhecimento prévio dos discentes e os aspectos primordiais do assunto abordado, oferecendo sínteses, recapitulações e referências para fundamentação teórica. Portanto, a maneira como o professor conduz as interações em sala de aula pode contribuir, em maior ou menor intensidade, para a produção de significados sobre um determinado tema e a valorização da autonomia discente (ZABALA, 2008).

Dessa forma, para que a introdução de um tema atual e relevante no contexto do sistema de saúde público brasileiro, como o da judicialização da saúde, motivasse o envolvimento discente e fizesse sentido para o trabalho dos futuros profissionais de enfermagem, buscou-se integrar a aula expositiva com outras ferramentas pedagógicas ativas.

\section{Objetivo}

Relatar a experiência do uso de ferramentas facilitadoras do processo ensino-aprendizagem em sala de aula, junto a discentes de graduação em enfermagem, para auxiliá-los a compreender e refletir sobre o processo da judicialização da saúde.

\section{Metodologia}

Relato de experiência produzido no contexto da disciplina Organização e Gestão em Saúde e Enfermagem na Atenção Básica, ministrada no sétimo período do curso de graduação em Enfermagem em uma instituição pública de ensino universitário do interior paulista.

A disciplina tem como objetivo desenvolver conhecimentos, habilidades e atitudes nos estudantes para que eles compreendam a organização e a gestão do sistema público de saúde brasileiro nas três esferas governamentais, sob a perspectiva da Atenção Básica. No contexto da disciplina, diferentes abordagens metodológicas são utilizadas para o desenvolvimento dos conteúdos, uma vez que ela está organizada em dois blocos: teórico e teórico-prático (UNIVERSIDADE DE SÃO PAULO, 2018).

No bloco teórico, as facilitadoras empregam a estratégia da aula invertida (BOLLELA \& CESARETTI, 2017), com leitura dirigida via plataforma Moodle. Nos momentos presenciais, há a aplicação de testes e aulas expositivo-dialogadas. No bloco teórico-prático, as atividades são desenvolvidas por meio de momentos de dispersão nos serviços de Atenção Básica para conhecer sua dinâmica, levantar necessidades de saúde e reconhecer a atuação da enfermagem, de concentração para reunir e sintetizar em subgrupos as situações vivenciadas na dispersão, de sintese para compartilhar com os demais colegas da turma, por meio de seminários, os aspectos apreendidos nas etapas anteriores e de avaliação (UNIVERSIDADE DE SÃO PAULO, 2018). 
A experiência relatada se enquadra no conteúdo programático referente à responsabilidade da gestão de saúde municipal e se articula com alguns dos demais conteúdos disciplinares na medida em que aspectos teóricos (normativos e operacionais) macro e micropolíticos do sistema de saúde são confrontados com a prática nos serviços de saúde. O tema da judicialização da saúde é tratado exclusivamente na disciplina, apesar da discussão do direito à saúde permear outros momentos no curso de graduação.

Anteriormente ao dia da aula, um artigo científico (CARVALHO \& DAVID, 2013) e uma reportagem (SEGATTO, 2012) atuais sobre o tema da judicialização da saúde foram disponibilizados aos alunos para leitura prévia.

No dia da aula, inicialmente, perguntou-se aos alunos o que eles entendiam sobre a judicialização da saúde. As facilitadoras solicitaram que compartilhassem, espontânea e livremente, ideias relacionadas ao tema sem se preocuparem com o certo ou o errado. Vários aspectos foram verbalizados pelos alunos e anotados no quadro branco pelas facilitadoras. Essa técnica, conhecida como brainstorming ou tempestade cerebral, permitiu o registro de pensamentos sem julgá-los (MASETTO, 2015).

Em seguida, aplicou-se uma dinâmica de grupo para auxiliar os graduandos no reconhecimento do cenário internacional sobre o nascimento e a evolução dos direitos, do direito à saúde e do fenômeno de judicialização da saúde no Brasil. A dinâmica de grupo é definida, pela psicologia social, como uma forma de comunicação, interação e relação coletiva que propicia a aprendizagem (DIAS \& SILVA NETO, 2012; SILVA, 2008).

O conteúdo da dinâmica foi confeccionado de modo lúdico - a partir de perguntas e respostas digitadas e recortadas separadamente em folha A4 - obedecendo à ordem cronológica e histórica sobre os assuntos acima citados. A técnica foi aplicada em duas etapas: na primeira, os alunos divididos em subgrupos juntaram e organizaram as perguntas às respostas dos itens formulados. $\mathrm{Na}$ segunda, apresentaram o produto das discussões aos demais membros da turma, interpretando o seu teor.

No tema nascimento e evolução dos direitos no cenário internacional, foram preparadas questões referentes ao conceito universal de direitos, à função de documentos jurídicos no reconhecimento dessas condições e aos principais documentos internacionais que têm construído e garantido o direito à saúde na esfera mundial.

No tema direito à saúde, as questões versaram sobre a garantia do direito à saúde no Brasil, com destaque para as políticas públicas sociais como meio de assegurar esse direito social, os modelos de ação dos sistemas de proteção social do Estado, a Constituição Federal de 1988 e algumas leis, normas e portarias que têm tentado garantir o direito à saúde. E no tema judicialização da saúde, as questões trataram sobre a definição desse fenômeno, o início da interferência do Poder Judiciário no Executivo, bem como as vertentes que auxiliam a sua compreensão.

Após a aplicação da dinâmica, foram expostos aos alunos alguns resultados dessa realidade no município do interior paulista - sede da instituição de ensino -, evidenciando o perfil sociodemográfico e epidemiológico dos usuários que impetraram ação contra a gestão pública de saúde, junto a uma das vias de acesso à Justiça brasileira - divulgados por uma pesquisa recente de mestrado (RODRÍGUEZ, 2014).

Em seguida, fez-se uma provocação utilizando uma adaptação do dilema ético-moral de Thomson (1985) conhecido como The trolley problem ou o Dilema do bonde, que expõe uma situação e seus possíveis rearranjos que determinam as decisões tomadas na perspectiva da ética e moral. A adaptação do dilema foi sugerida em um trabalho realizado na cidade de Petrolina-PE que, indiretamente, se relaciona à judicialização da saúde: Um de vocês está dirigindo um carro em uma rodovia e avista um ciclista cruzando a via. Você não conseguirá frear a tempo e atropelará o ciclista. Entretanto, se você desviar da bicicleta, atingirá um ponto de ônibus onde vinte pessoas aguardam o transporte coletivo. O que fazer? Atingir o ciclista ou as pessoas no ponto de ônibus? (ANAPE, 2014). 
Então, perguntou-se aos graduandos o que fariam nesse caso, considerando os resultados da pesquisa de mestrado, a leitura prévia do artigo e da reportagem sobre o tema que abordam aspectos relevantes dessa realidade para o trabalho da enfermagem.

\section{Resultados}

Inicialmente, os alunos se mostraram surpresos tanto com o tema da aula quanto com as estratégias selecionadas para apresentar, debater e refletir sobre o assunto. Entretanto, foram receptivos e participativos na aplicação da tempestade cerebral e da dinâmica, na reflexão sobre o dilema e na discussão proposta logo em seguida.

Durante a primeira etapa da dinâmica de grupo, todos os alunos dos quatro subgrupos leram o seu conteúdo e discutiram o seu teor para formar os pares correspondentes entre as perguntas e respostas. Na segunda etapa, apenas os líderes dos subgrupos se manifestaram diante dos demais colegas da turma, ao exporem e comentarem os itens agrupados. Nesse momento, as facilitadoras estimularam a participação dos demais membros dos subgrupos, especialmente em divergências observadas no agrupamento dos itens, para sanar possíveis dúvidas sobre um dos três temas abordados.

$\mathrm{Na}$ apresentação da realidade do processo de judicialização da saúde no município, os discentes sinalizaram desconhecer os itens solicitados, as faixas etárias, as doenças prevalentes e o número total dos usuários - dados que caracterizaram a população impetrante.

Nessa etapa da aula, alguns discentes compartilharam casos na família ou de conhecidos que buscaram a via judicial para garantir o direito à saúde e verbalizaram desconhecer também, até então, o complexo sistema que envolve a tutela desse direito pela via judicial. Com isso, emitiram opiniões sobre a reportagem, produzindo conexões entre a premissa "saúde para todos" e os aspectos que envolvem a garantia dos direitos individuais e coletivos, trazendo ainda outros casos que repercutiram nacionalmente.
$\mathrm{Na}$ provocação feita para facilitar o entendimento desse fenômeno para o trabalho da enfermagem, houve discussão paralela entre os graduandos, na medida em que eram indagados sobre qual decisão tomariam na rodovia. Alguns propuseram novas opções para evitar uma das duas possibilidades que se apresentaram como alternativas, tais como: sair no primeiro retorno da rodovia, pular de dentro do carro ou ir freando e desviando o carro devagar até conseguir passar entre o ciclista e as pessoas no ponto de ônibus, especialmente se entre as pessoas envolvidas na situação houvesse algum familiar ou conhecido.

$\mathrm{E}$, ao final, as facilitadoras resgataram os resultados da pesquisa de mestrado (RODRÍGUEZ, 2014), o conteúdo do artigo (CARVALHO \& DAVID, 2013), da reportagem (SEGATTO, 2012) e da dinâmica de grupo e as decisões tomadas frente ao dilema ético-moral do direto à saúde, confrontando-os com os pensamentos discentes anotados no quadro branco no início da aula.

As facilitadoras perceberam que esses pontos trazidos pelos alunos no início da aula foram esclarecidos, e a forma como a aula foi conduzida contribuiu para que eles refletissem sobre o papel da enfermagem na compreensão e valorização dos distintos e complexos aspectos que envolvem a garantia do direito à saúde individual e coletiva no processo de judicialização da saúde.

\section{Conclusão}

A utilização de técnicas participativas no processo de ensino-aprendizagem para o tema da judicialização da saúde, inicialmente, surpreendeu os acadêmicos de enfermagem, pois essas estratégias educativas não têm sido incorporadas à prática docente, de forma usual, nas disciplinas básicas da área da saúde.

A tempestade de ideias permitiu uma rápida e espontânea introdução sobre o tema. A dinâmica de grupo aplicada nessa disciplina também promoveu interação discente nos subgrupos, esclarecendo dúvidas sobre os assuntos abordados, semelhantemente à aplicação dessa estratégia em outra disciplina (RODRÍGUEZ, FERREIRA, 
MISHIMA, VILLA \& PALHA, 2016). Os resultados da pesquisa de mestrado aproximaram os alunos da realidade do município desconhecida por alguns, a qual, ao mesmo tempo, proporcionou um resgate de vivências pessoais por outros.

O conteúdo da reportagem que remeteu a outros casos nacionalmente conhecidos, o dilema ético-moral e o debate final instigaram a reflexão sobre o trabalho do enfermeiro no processo de judicialização da saúde e nas questões que envolvem o direito à saúde.

Portanto, pode-se indicar que as técnicas aplicadas na aula da disciplina Organização e Gestão em Saúde e Enfermagem na Atenção Básica criaram possibilidades de conhecer, refletir e produzir um saber em conjunto essencial para o processo de formação social dos futuros enfermeiros, complementadas pelas demais estratégias de ensino utilizadas na disciplina.

\section{Referências Bibliográficas}

ANASTASIOU, Léa Graças Camargos \& ALVES, Leonir Pessate. Processos de Ensinagem na Universidade: Pressupostos para as Estratégias de Trabalho em Aula. 5 ed. Joinville: Univille, 2005.

ASSOGIAÇÃO NAGIONAL DOS PROGURADORES DOS ESTADOS E DO DF (ANAPE). A Judicialização da Saúde: Provocações sobre o Tema e o Exemplo Petrolina-PE. Brasília: ANAPE, 2014. Disponível em: $<$ http://anape.org.br/site/wp-content/uploads/2014/07/ Arquivo_tese-5.pdP $>$. Acessado em 3 maio 2018.

BOLLELA, Valdes Roberto \& CESARETTI, Mario Luís Ribeiro. "Sala de Aula Invertida na Educação para as Profissões de Saúde: Conceitos Essenciais para a Prática". Revista Eletrônica de Farmácia, Goiânia, vol. 14, n. 1, 2017, pp. 39-48.

BRASIL. Código Penal, Código de Processo Penal, Constituição Federal, Legislação Penal e Processual Penal. 16 ed. São Paulo: Revista dos Tribunais, 2014, pp. 23-154.

CARVALHO, Eloá Carneiro \& DAVID, Helena Maria Scherlowski Leal. "Judicialização da Saúde,
Problema e Solução: Questões para a Enfermagem". Revista Enfermagem Uerj, Rio de Janeiro, vol. 21, n. 4, out./dez. 2013, pp. 546-50.

DIAS, Maria Sara de Lima \& SILVA NETO, Pedro Moreira. Dinâmica de Grupo: Aspectos Teóricos e Práticos. Petrópolis: Vozes, 2012.

MASETTO, Marcos Tarciso. Competência Pedagógica do Professor Universitário. 3 ed. São Paulo: Summus, 2015.

RODRIGUEZ, Anna Maria Meyer Maciel. O Processo da Judicialização da Saúde como Via de Acesso à Atenção Integral: o Retrato de um Município de Grande Porte do Estado de São Paulo. Dissertação, Escola de Enfermagem de Ribeirão Preto, Ribeirão Preto, Universidade de São Paulo, 2014.

; FERREIRA, Marianna; MISHIMA, Silvana Martins; VILLA, Tereza Cristina Scatena \& PALHA, Pedro Fredemir. "Dinâmica de Grupo como Estratégia Facilitadora do Processo de Ensinoaprendizagem: Relato de Experiência". Revista de Enfermagem UFPE On-Line, Recife, vol. 10, supl. 5, nov. 2016, pp. 4364-4369.

SEGATTO, Cristiane. "O Paciente de R\$ 800 mil". Época. 2012. Disponível em: <http://revistaepoca. globo.com/tempo/noticia/2012/03/o-paciente-de-r800-mil.html>. Acessado em 4 maio 2018.

SILVA, Jorge Antônio Peixoto. "O Uso de Dinâmicas de Grupo em Sala de Aula: um Instrumento de Aprendizagem Experiencial Esquecido ou ainda Incompreendido?". Revista Saber Cientifico, Porto Velho, vol. 1, n. 2, jul./dez. 2008, pp. 82-99.

THOMSON, Judith Jarvis. "The Trolley Problem Source". Yale Law Journal, New Haven, vol. 94, n. 6, may. 1985, pp. 1395-1415. Disponível em: <http:// waleszczynski.pl/wp-content/uploads/sites/4/2016/02/ trolley_j_thomson.pdf $>$. Acessado em 3 maio 2018.

UNIVERSIDADE DE SÃO PAULO. Escola de Enfermagem de Ribeirão Preto. Departamento Materno-infantil e Saúde Pública. Disciplina ERM0310 - Organização e Gestão em Saúde e Enfermagem na Atenção Básica, 2018. Disponível em: <https://uspdigital.usp.br/jupiterweb/obterDisciplina?sgldis=ERM0402\&verdis=5> . Acessado em 6 maio 2018.

ZABALA, Antoni. A Prática Educativa: Como Ensinar. Porto Alegre: Artmed, 2008.

Publicado em 12/06/2018. 